\title{
Design of Evaluation Index System of Electric Power Multilateral Trading Market Operation
}

\author{
Li Xin ${ }^{1}$, Zhaoqing $\mathrm{Fu}^{1}$, Kangping Liu ${ }^{1}$, Jiang $\mathrm{Xu}^{1 *}$, Baoming $\mathrm{Ma}^{1}$ \\ ${ }^{1}$ Inner Mongolia Power (Group) Co., Ltd, Hohhot, Inner Mongolia Autonomous Region, 010020, China
}

\begin{abstract}
With the deepening of the reform of the electric power system and the continuous improvement of the demand level of electric power users, the psychological expectations of the market subjects have also undergone profound changes, and it is necessary to gradually strengthen and expand the key indicators and analysis dimensions that can reflect the operation situation of the electric power market, so as to adapt to the existing statistical analysis business needs. According to the current business content and demand of electricity market, this paper establishes a scientific and comprehensive evaluation index system of electricity market from the perspectives of market supply and demand, market structure, market behavior and market discipline. The system can reflect the development of power market comprehensively and objectively.
\end{abstract}

\section{Introduction}

With the deepening of the power system reform, improve power users of the level of demand, the market main body of the psychological expectations also has profound changes, trading center as the main body, service based services to meet the current market main body, based on the need to continue to expand customer service content, as the market main body to provide convenient and personalized trading and derivatives ${ }^{[1-2]}$. The power market business involves various kinds of information, such as power transaction data and thermal coal market data, and the data volume is huge, and the distribution is relatively scattered. For a single market member, the workload of collecting and storing these data is very large, and it needs to invest special and huge manpower and time to obtain effective information related to its own operation. A reasonable operation evaluation index system can help market members to understand the market operation status, grasp the market trend, reduce the operation cost, reasonably participate in transactions, and improve the overall economic benefits. Therefore, it is of great significance to construct the evaluation index system of electricity multilateral trading market operation ${ }^{[3-4]}$.

Make statistical analysis of the power market by referring to the principles and methods of index system construction in similar directions, and change the business contents and demands of the existing power market transactions. This study constructs a scientific and comprehensive evaluation index system of power multilateral trade market operation from the perspectives of market supply and demand, market structure, market constraint, and influence of power trading activities of market behaviors ${ }^{[5-7]}$.

\section{The overall objectives of the operation evaluation index system}

The evaluation method constructed in this paper effectively identifies and decomposes the benefits of each business link in the operation of the multilateral trading market of electric power, puts forward the corresponding evaluation and calculation method, and establishes a quantitative calculation model. Based on advanced mathematical methods, technical economics and empirical economics theory, various mathematical decoupling and mapping techniques for redundant information are applied to put forward evaluation methods for evaluating different types of benefits ${ }^{[8-9]}$. Through scientific decomposition, screening and induction, the characteristic benefit set of power multilateral trading market operation business is formed. In order to meet the requirement of comprehensiveness and avoid overlapping of benefits, comprehensive evaluation models for various benefits of different trading centers are established.

Second, using data mining technology, the use of the data warehouse and on-line analytical processing technology, operation of power grids data for effective management and scientific analysis, to solve a large number of data and the technical bottleneck of information islands distributed data resources is difficult to quickly extract valuable knowledge to effectively support the decision making problems, in accordance with the "integrated information, build the model, extract knowledge", eliminate information islands, from a large number of power grid operation business data mining 
information and extract knowledge, support power multilateral trading market intelligence analysis and assessment of the operation ${ }^{[10-11]}$.

\section{Construction of operation evaluation index system}

According to each transaction center, the power grid, power generation enterprises and power users of electric power market demand big data information services, for each object involved in electric power market transaction behavior analysis, the research electric power market transaction the causal relationship between each stage, the divisions of the service object on the basis of constructing index set, and then for each index set from the market overall operation, bidding strategies, such as power generation strategy Angle, build a complete evaluation index system of electricity multilateral trading market operation.

\subsection{Electricity Trading Index}

3.1.1 Electricity trading price index. The power transaction price index is the ratio of all marketized user transaction prices in the statistical period and the base period, whether in the market of single power buyer or in the market of two-sided bidding.

3.1.2 Market activity index. The proportion of traded electricity accounted for the whole society's electricity consumption reflects the market scale; Through the proportion of the users participating in the market transactions in all the admittance users, it reflects the enthusiasm of the main body to participate in the transaction; The proportion of electricity volume in the declared electricity volume in the form of floor trading such as centralized bidding and listed trading reflects the efficiency of market trading. Then set the corresponding weight of each index.

3.1.3 Electricity trading price index. According to the power trading price index and the market activity index, the weight coefficient is set to form the composite index.

3.1.4 Electricity trading price index. Generally, through PMI, CPI, stock index and other indicators to show.

\subsection{Market supply and demand}

3.2.1 Aggregate market demand. If the market of a single power buyer, such as the external power supply market, the total demand of the market is the purchase quantity of the market, that is, all the bilateral external power supply contract quantity. If electricity is purchased and sold in bilateral bidding markets, such as alternative power generation market, the total market demand is the sum of the subscribed amount of all the transferees.
3.2.2 Total market supply. The total market supply is the sum of the declared amount of all the electricity sellers, whether it is the market of a single power buyer or the market of electricity purchase and sale through bilateral bidding.

3.2.3 Market supply/demand ratio. The market supply and demand ratio index can reflect the market supply and demand intuitively and effectively. The market supplydemand ratio is defined as:

$$
S D R=\frac{Q_{S}}{Q_{D}}
$$

So $Q_{D}$ is the forecast of aggregate demand in the market, and $Q_{S}$ is aggregate supply.

When $S D R \rightarrow 1$ or less than 1 , the market is short of supply, power generators have monopoly power, can control the market price. Therefore, the smaller the index value, the more the market tends to monopolize the market; The larger $S D R$ is, the more sufficient market supply is and the more competitive the better, under the perfect competition market $S D R \rightarrow \infty$.

\subsection{Market structure}

3.3.1 Electricity trading price index. Supplier status indicators are used to study the supplier's position in the market, bidding strength and the ability to influence the market price. The market share indicator is the most important bidding status indicator, which reflects the participant's competitive ability in terms of electricity.

Market share refers to the proportion of the trading volume of a single market participant (bidding power plant or power company) in the total number of market participants. Represented by:

$$
s_{i}=q_{i} / \sum q_{i}
$$

$q_{i}$ is the declared space or trading volume of the supplier, and the declared space share and trading volume share can be obtained.

3.3.2 Top-m share index. The Top-m index is based on the market's historical transaction data, which can directly reflect the degree of market concentration.

Top-m share refers to the market share of the largest $\mathrm{m}$ suppliers in the market. This index can be calculated according to the transaction situation within a period of market history. In general industrial fields, Top-4 index is commonly used, that is, $\mathrm{m}=4$, and Top- 4 index $>65 \%$ indicates that the market has the nature of oligopoly. The larger the index, the higher the degree of market concentration. 
3.3.3 Herfindahl-Hirshman Index. HerfindahlHirshman Index (HHI) is the most widely used index to reflect the market structure. HHI index can be measured by the sum of squares of market shares held by suppliers in each market:

$$
\left.H H I=\sum_{i=1}^{N}\left(100 * s_{i}\right)^{2}\right)
$$

$S_{i}$ is the market share of the ith market supplier.

The monopolistic market HHI is 10000 , and the perfectly competitive market $\mathrm{HHI}$ tends to 0 . In general, markets where $\mathrm{HHI}$ is less than 1800 should be considered more competitive. HHI index mainly depends on the number of market participants and the size of market share: the fewer market members and the more concentrated market resource allocation, the larger $\mathrm{HHI}$ is, indicating the greater the possibility of abusing monopoly power in the market.

\subsection{Market discipline}

The term "external transmission capacity" refers to the remaining capacity of the transmission line from the province to the other province during the transaction of external transmission market. The so-called residual capacity refers to the residual value of the total transmission capacity of the tie line after deducting the scheduled transmission volume of the tie line.

The volume of external power market should not exceed the capacity of external power transmission. Even though the demand of external power supply market, namely the bilateral external power supply contract is large and the supply capacity of units in this province is sufficient, the growth of external power supply is sometimes restricted by the capacity of the tie line.

\subsection{The market cost}

3.5.1 Power generation cost. The cost of the generator is an important index to measure the bidding position of the generator, and also an important factor to determine the market price and transaction. Power generation cost, that is, the average power generation cost, that is, the cost paid by the power generation side to produce each kilowatt hour of electricity. This figure is not currently available from the market technical support system and can only be estimated based on the price quoted by the generator. When the competition is very fierce, generators compete with each other on the cost of electricity generation. The lower the cost is, the more space the generators have to reduce the price and the more ability they have to hold down the price and seize the share.

3.5.2 The opportunity cost. Opportunity cost is the most commonly used concept in economic decision-making. Any investment, transaction or business will occupy certain resources, such as human resources, materials and time, etc. Opportunity cost refers to the maximum value created by these resources that are not used for the current business.

For power producers who sell electricity in the market, participating in market transactions can obtain the electricity charges of sold electricity. Opportunity cost refers to the maximum profit that can be brought by the retained power generation capacity without participating in market transactions. For example, the power producers can sell this part of electricity through other markets.

\subsection{Market behavior}

3.6.1 Rate of quotation. The ratio of quoted high price is defined as the proportion of the total quantity of electricity declared by the market supplier in a given period that is close to the highest price. The larger this indicator is, the more risks the supplier is willing to take in order to obtain higher returns.

3.6.2 High bid winning rate. This index is proposed in this paper according to the characteristics of the market. It reflects the cooperation between suppliers' bidding strategies and their own strength through the comparison of suppliers' transaction conditions and declaration conditions, and evaluates the success rate and market power of suppliers' strategies.

High bid winning rate $=\frac{\text { Variable that bid high and won }}{\text { Quoted high prices for electricity }}$

The high bid winning rate is a comprehensive index, which reflects the situation that the power plant not only deliberately increases the declared price, but also gets close to the declared electricity amount. The higher the winning rate of high price, the stronger the supplier's ability to control the market price and the greater the market power.

3.6.3 The retention rate. The market capacity strategy reflects the degree of power supply control by the supplier, which can be reflected by the retention ratio:

$$
\text { the retention rate }=\frac{c_{i}-q_{i}}{c_{i}}
$$

Where $c_{i}$ is the generating capacity and $q_{i}$ is the actual declared capacity.

The higher the retention rate is, the more the supplier controls the supply, and the more obvious the intention to raise the price. Indicators can also be used for the overall analysis of the market, the overall retention ratio of the market will increase, will lead to tight supply, market prices are driven up.

\section{Conclusion}

At present, China's electric power market is in the management period of comprehensively deepening the reform, the electricity selling side reform is gradually recommended, new market players emerge, trade varieties 
are more abundant, and the electric power market operation faces more complex and diversified forms. This paper selects the key indicators of the power market for evaluation and analysis, and constructs a scientific and comprehensive power multilateral trade market operation evaluation index system from the aspects of market supply and demand, market structure, market behavior and the impact of market constraints on power trading activities.

\section{References}

1. Guo Y, Pan M, Fang Y, et al. (2013) Decentralized coordination of energy utilization for residential households in the smart grid. IEEE Transactions on Smart Grid, 4(3): 1341-1350.

2. Cai Yu, Lin Jin, Wan Can, et al. (2016) A bi-level stochastic programming approach for strategic active distribution network operation in electricity market. Proceedings of the CSEE, 36(20): 5391-5402.

3. Song Y, Lin J, Hu Z, et al. (2016) Energy distribution network: infrastructure, operation mode and market mechanism. Proceedings of the CSEE, 36(21): 57765787.

4. Kok K, Widergren S. (2016) A society of devices: integrating intelligent distributed resources with transactive energy. IEEE Power and Energy Magazine, 14(3): 34-45.

5. Apostolopoulou D, Bahramirad S, Khodaei A. (2016) The interface of power: moving toward distribution system operators. IEEE Power and Energy Magazine, 14(3): 46-51.

6. Rahimi F, Ipakchi A, Fletcher F. (2016) The changing electrical landscape: end-to-end power system operation under the transactive energy paradigm. IEEE Power and Energy Magazine, 14(3): 52-62.

7. Kristov L, De M.P., Taft J.D. (2016) A tale of two visions: designing a decentralized transactive electric system. IEEE Power and Energy Magazine, 14(3): 63-69.

8. Chen S, Liu C. (2017) From demand response to transactive energy: state of the art. Journal of Modern Power Systems and Clean Energy, 5(1): 10-19.

9. Kim M, Song S, Jun M. (2016) A study of block chain-based peer-to-peer energy loan service in smart grid environments. Advanced Science Letters, 22(9): 2543-2546.

10. Nisan N, Ronen A. (2007) Computationally feasible VCG mechanisms. Journal of Artificial Intelligence Research, 29(1); 19-47.

11. Menniti D, Costanzo F, Scordino N, et al. (2009) Purchase-bidding strategies of an energy coalition with demand-response capabilities. IEEE Transactions on Power Systems, 24(3): 1241-1255. 